This item was submitted to Loughborough's Research Repository by the author.

Items in Figshare are protected by copyright, with all rights reserved, unless otherwise indicated.

\title{
Examination of silver-graphite lithographically printed resistive strain sensors
}

PLEASE CITE THE PUBLISHED VERSION

http://dx.doi.org/10.1016/j.sna.2006.10.003

PUBLISHER

(c) Elsevier

VERSION

AM (Accepted Manuscript)

LICENCE

CC BY-NC-ND 4.0

REPOSITORY RECORD

Hay, Gareth I., Darren J. Southee, Peter S.A. Evans, David J. Harrison, George Simpson, and Blue J. Ramsey. 2019. "Examination of Silver-graphite Lithographically Printed Resistive Strain Sensors". figshare. https://hdl.handle.net/2134/8474. 
This item was submitted to Loughborough's Institutional Repository (https://dspace.lboro.ac.uk/) by the author and is made available under the following Creative Commons Licence conditions.

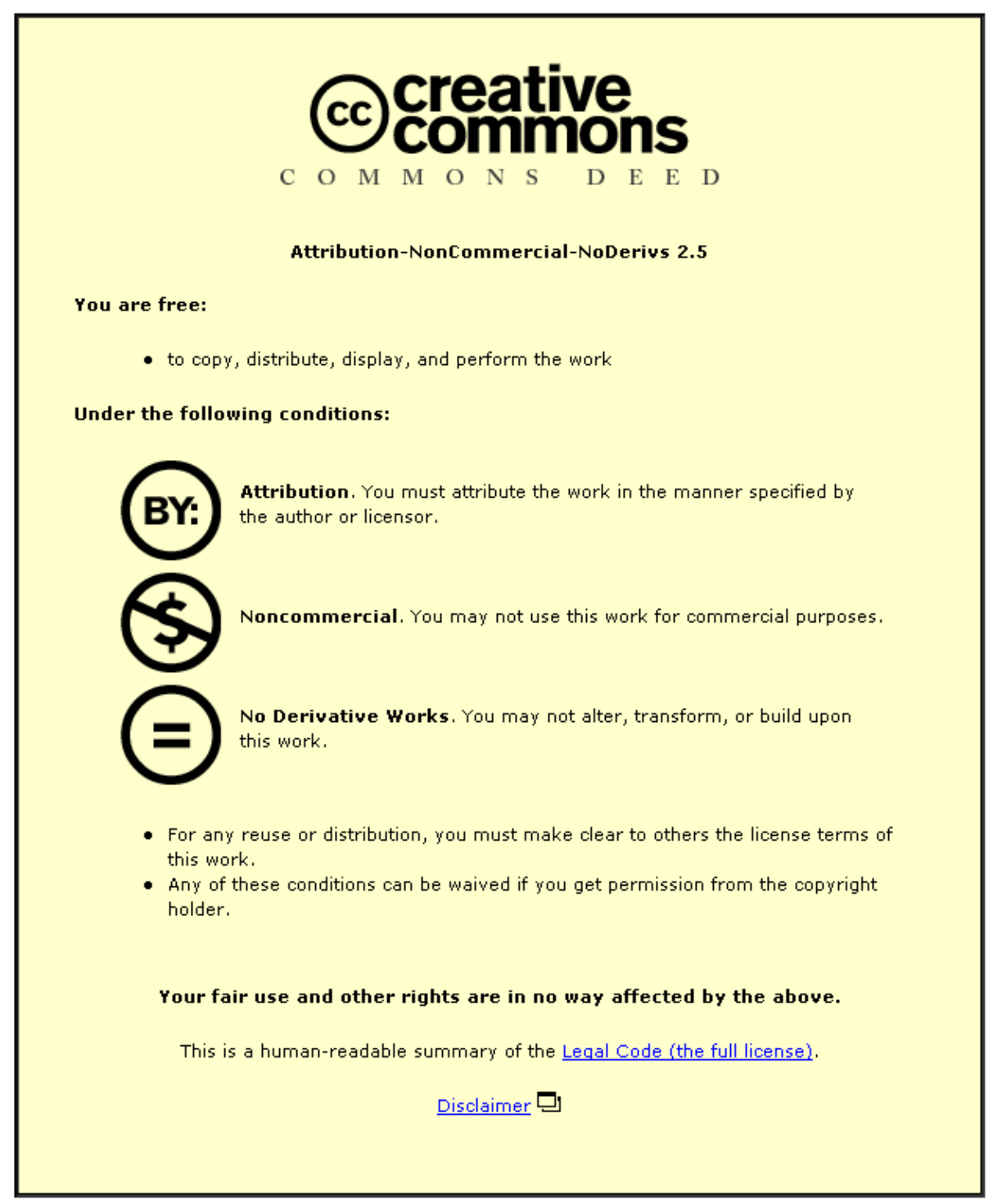

For the full text of this licence, please go to: http://creativecommons.org/licenses/by-nc-nd/2.5/ 


\title{
Examination of Silver-Graphite Lithographically Printed Resistive Strain Sensors
}

\author{
Gareth I. Hay, Darren J. Southee, Peter S. A. Evans, David J. Harrison, George Simpson and Blue J. Ramsey \\ Cleaner Electronics Research Group, School of Engineering and Design, Brunel University, Uxbridge, UB8 3PH. UK
}

\begin{abstract}
This paper reports the design and manufacture of three differing types of resistive strain sensitive structures fabricated using the Conductive Lithographic Film (CLF) printing process. The structures, utilising two inks prepared with silver and graphite particulates as the conductive phase, have been analysed to determine electrical and mechanical properties with respect to strain, temperature and humidity when deposited on four alternative substrate materials (GlossArt, PolyArt, Teslin and Melinex).
\end{abstract}

Key words: Printed strain sensors, Offset Lithography, Conductive Lithographic Film, Conductive Inks

\section{Introduction}

Resistive type strain gauges supplanted other techniques of strain measurement, such as extensiometers, in the 1930's as the most popular method of experimental strain analysis with the release of the first commercially produced resistive wire strain gauge, the SR-4 [1].

The operation of a resistive strain gauge relies on the linear relationship between the change in resistance and the change in length of a conductor due to an applied load. Average unit strain, capable of being determined by such devices, can be summarised as the "total deformation of a body in a given direction divided by the original length in that direction"[1].

Manufacturing techniques for the production of resistive strain gauges have modified over time from thin diameter wire cemented in a grid formation on a paper backing material, employed for SR-4 structures, to photo resist, acid etched grids formed on alloy clad polymer substrates. Disadvantages associated with the later manufacturing technique include the production of toxic waste material and slow speed of fabrication.

\subsection{CLF Process}

The Conductive Lithographic Film (CLF) process was originally developed as an alternative for etched resinlaminate circuit boards. The technique utilises standard offset lithographic printing technology used in the mass production of books and magazines. The CLF process possesses a number of key advantages over more traditional forms of electronic circuit board fabrication [2]:

- High production speed (6,000 - 10,000 impressions/hour);

- Good resolution of image (80 - 100 micron track with 60 micron gap easily achievable);

- Low cost (low ink volume determining that substrate material proves the largest expense);

- Ability to produce flexible electronic circuits and systems;
- Reduced environmental impact (less energy, reduction in material use, easier disposal, elimination of toxic heavy metals such as lead).

Electrically conductive ink films can also be printed on a wide range of flexible substrates including paper and polymer films.

A range of passive components and sensor structures have been manufactured by the CLF process by designing structures that exploit the electrical properties of the printed ink films [3-5]. CLF conductors printed on flexible polymer materials have been found to exhibit a change in their electrical resistance when deformed, lending themselves to resistive strain gauge applications. The purpose of this research is to understand in greater detail the electrical and mechanical properties of two differing conductive lithographic inks utilised for strain sensor applications in three different configurations. Changes in structure resistance due to strain, relative humidity and temperature are described in this paper.

\subsection{Previous work}

Polymer thick film resistor strain gauges have been achieved in the past by screen printing carbon loaded inks onto metallic or ceramic substrates in solid film format, and have achieved electrical and mechanical properties comparable to those attained by conventionally manufactured sensors [6-11]. Linearity values between 86 - 99\% have been recorded for differing configurations of structures while hysteresis values of $3-4 \%$ have been obtained over several repeated loading and unloading cycles to 500 micro strain [11]. Other work detailing lithographically printed resistor arrays as pressure sensors indicate a similar problem with hysteresis but conclude that the magnitude of hysteresis decreases with loading unloading cycles and amounts to about 1\% after three cycles [3].

Work previously published by the author details single ink, single track resistive type strain sensors fabricated using the CLF process utilising a silver particulate loaded ink [13]. The structures detailed possess a grid format similar to that employed by commercially available strain sensitive structures. A comparison study was undertaken 
on structures deposited on six differing substrates. Linearity values of $88-97 \%$ were achieved on loading unloading cycles up to 2000 micro strain, depending on substrate material.

\section{Experimental}

\subsection{Structure configuration}

Three different structure configurations printed on four alternative substrates have been considered for comparison. All structures were designed to attain active gauge lengths of $25 \mathrm{~mm}$ and gauge areas of $312.5 \mathrm{~mm}^{2}$. Manufacture of each structure involved the creation of several offset lithographic printing plates. Suitable artwork was generated using a graphical software package (Adobe Illustrator 9.0v), after which Magnus Litho Ltd., Reading, UK, manufactured the printing plates. Standard lithographic plate fabrication techniques were followed and the artwork was transferred to Fuji VPSE metal printing plates.

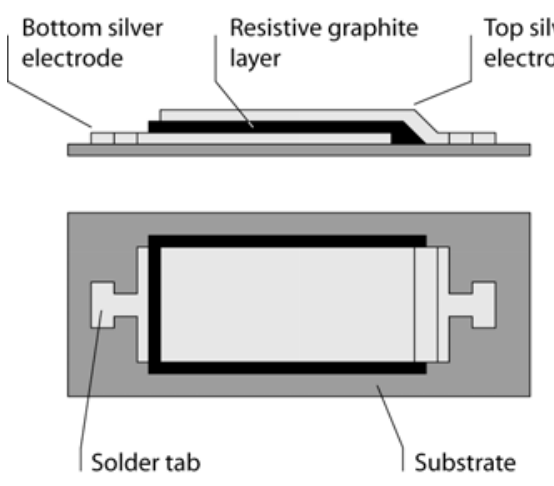

Fig. 1. Silver - Graphite Sandwich Configuration
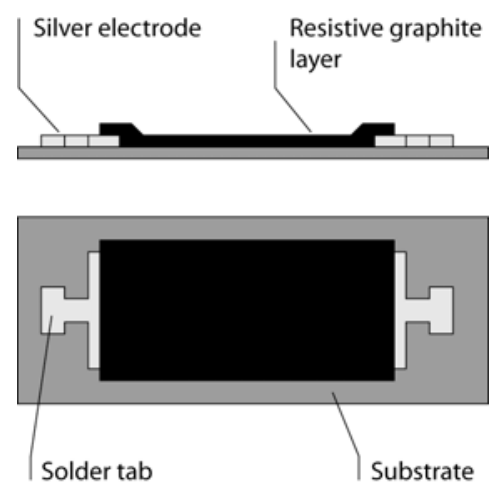

Fig. 2. Silver - Graphite Planar Configuration

The first structure comprises a graphite based sensing layer, sandwiched between silver electrodes, as depicted in Fig. 1. Three printing plates were required for the manufacture of these structures. The first plate imaged the bottom silver electrode whilst the second and third plates imaged the resistive graphite layer and the top silver electrode, respectively. As with all structures involving more than one printing plate, much care was taken to ensure perfect registration between plates. Following standard CLF protocol, silver layers were printed three times to ensure an even distribution of ink.
The graphite layers were printed nine times to ensure a solid film with no pores was deposited.

The second structure comprises two silver electrodes connected via a solid graphite layer in a planar fashion as depicted in Fig. 2. For comparison reasons, as with the sandwich structures, the graphite portion consisted of nine individually deposited ink films.
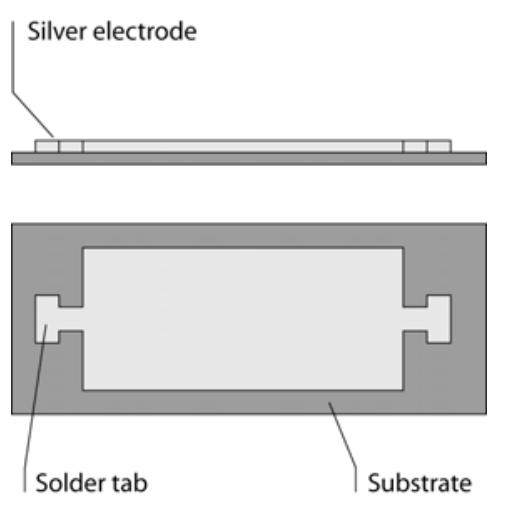

Fig. 3. Plain Silver Configuration

The final structure format followed the planar design of the second structure with the exception that it was composed entirely from a silver deposited ink, as depicted in Figure 3.

\subsection{Ink formulation}

The silver ink employed during print trials was the standard silver loaded mixture developed by Brunel University for compatibility with the offset lithographic printing process [12]. The ink constitutes $80 \%$ silver particulate by weight ( 1 micron mean size) and achieves a sheet resistance of approximately 0.15 ohms per square $(\Omega / \square$, dependant on substrate), which is in agreement with previous work on conductive mixtures [14]. The vehicle portion of the ink comprises a large proportion of organic alkyd resin with traces of solvent and anti oxidant agents.

A suitable graphite based ink was developed by adapting the ink vehicle used in the silver loaded ink. Attention was given to developing an ink with a higher fraction of graphite compared to previous graphite lithographic inks thus reducing the sheet resistivity of the printed ink film while also conforming to the strict rheological criteria needed for lithographically printable inks [3]. The composition of the final ink is detailed in Table 1.

\begin{tabular}{cc}
\hline \hline Vehicle component & Percentage (w/w) \\
\hline Alkyd resin & 52.36 \\
Solvent & 14.96 \\
Anti oxidant & 0.68 \\
Graphite & 32 \\
\hline
\end{tabular}

Table 1. Composition of Graphite ink

The active particulates used in the graphite ink composed $32 \%$ by weight of the final ink mixture. Due to the increased bulk resistivity of graphite compared to silver, the approximate sheet resistivity attained by this ink was in the region of $1.5 \mathrm{k} \Omega$ per square dependent on 
surface roughness of the substrate material on which it was deposited.

\subsection{Fabrication of Structures}

Structures were fabricated using a sheet-feed lithographic printing press, model Heidelberg GTO-46. The first plate fitted to the machine imaged the bottom electrode of the sandwich structures, both electrodes of the planar structures, and the entirety of the plain silver structures. After three consecutive passes through the machine, spaced by 15 minutes per pass to prevent problems associated with set off, samples were permitted to air cure for 48 hours. After the first print run the printing press was cleaned thoroughly to remove any residue of silver ink, thus preventing the risk of contamination to the graphite ink.

The second printing plate imaged both graphite layers required for the fabrication of the sandwich and planar structures. During printing of the graphite ink, samples were passed through the press on nine consecutive occasions and, as with the first print run, 15 minutes was allowed between each pass to reduce problems of set off. Again, once printing was completed, samples were allowed to air dry for 48 hours and the press was cleaned thoroughly to prevent contamination of ink during the final print run.

The final print run imaged the top electrode of the sandwich structures. Three layers of silver were deposited to complete the sandwich structures in the method previously described.

Following printing, all samples were allowed to air cure for 7 days before constantan contact wires were attached to the solder tabs using a commercially available conductive adhesive (Circuitworks CW2400).

During print trials four differing substrates, ranging from materials designed for the graphics industry to engineering grade polymer films, were used as the base material onto which structures were formed. The details of each substrate are listed in Table 2.

\begin{tabular}{ccc}
\hline \hline Substrate & Material & Thickness $(\mu \mathrm{m})$ \\
\hline GlossArt & Coated paper & 100 \\
PolyArt & Polyethylene & 200 \\
Teslin & Polyethylene + silica & 191 \\
Melinex & filler & 36 \\
\hline \hline
\end{tabular}

Table 2. Substrate characteristics

As detailed previously [13], the sheet resistance of ink films deposited by the CLF process varies depending on the surface roughness of the substrate material considered. Table 3, details the nominal gauge resistance for each type of structure deposited on the four substrate materials concerned.

\begin{tabular}{cccc}
\hline \hline & \multicolumn{3}{c}{ Average Nominal Resistance $(\Omega)$} \\
& Sandwich & Planar & Plain \\
\hline GlossArt & 3.39 & 1547 & 0.91 \\
PolyArt & 1.68 & 3416 & 0.64 \\
Teslin & 1.36 & 317.5 & 0.75 \\
Melinex & 29.38 & 1728 & 1.02 \\
\hline \hline
\end{tabular}

Table 3. Substrate - Nominal resistance relationship

\subsection{Resistance - Strain measurements}

Aluminium beams dimensioning $6.5 \mathrm{~mm}$ x $34.5 \mathrm{~mm} \times$ $600 \mathrm{~mm}$ were utilised for resistance - strain measurements. Beams were prepared for gauge attachment using conventional strain gauge application techniques:

- $\quad$ Fixing area smoothed using fine grade Emery cloth and Ammonia water;

- Area cleaned using Phosphoric acid;

- Area neutralised with Ammonia water.

Before attachment of structures to test beams, the adhering surface was prepared with the application of an adhesion catalyst (200 Catalyst - C), following which a five minute drying time was observed before structures were cemented to the test beams using cyanoacrylate adhesive ( $\mathrm{M}$ - Bond 200) ensuring that any air pockets beneath the structures were eliminated. Subsequently, lead wires were soldered to the contact wires to aid attachment to data measuring equipment.

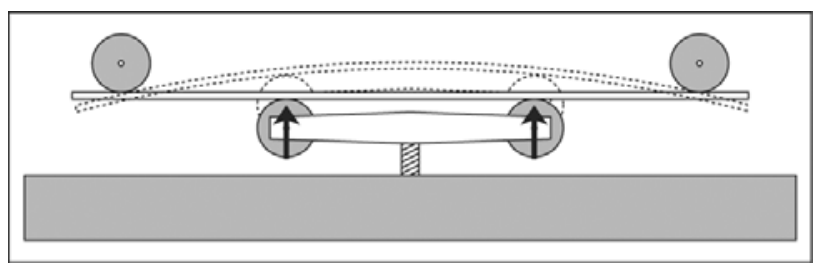

Fig. 4. Four - Point Deflection Jig

Testing was conducted using a four point deflection jig, Fig. 4, to ensure uniform beam deflection from $0-2000$ micro strain over four consecutive loading - unloading cycles. Changes in structure resistance were measured using a Fluke 189 True RMS Multimeter.

\subsection{Temperature - Resistance and Humidity - Resistance Measurements}

To determine the change in resistance of structures due to changes in ambient temperature and humidity a series of experiments were conducted using a Rotronic HygroGen humidity/temperature calibrator, fitted with a calibrated HygroClip ' $\mathrm{S}$ ' humidity/temperature sensor as reference.

During temperature testing, humidity was set to maintain a stable $40 \% \mathrm{RH}$ while temperature was cycled in $5^{\circ} \mathrm{C}$ increments from $15^{\circ} \mathrm{C}$ to $40^{\circ} \mathrm{C}$ over four repetitive cycles. Resistance measurements were recorded at each interval using the Fluke multimeter. A similar format was followed for relative humidity testing such that temperature was maintained at a constant $23^{\circ} \mathrm{C}$ and \%RH was incremented and decremented in 5\% steps from $20 \% \mathrm{RH}$ to $70 \% \mathrm{RH}$ over four repetitive cycles, whilst resistance measurements were recorded at each interval.

\section{Results}

\subsection{Relative Humidity - Resistance}

Figs. $5-7$ detail typical percentage change in resistance characteristics attained from each structure 


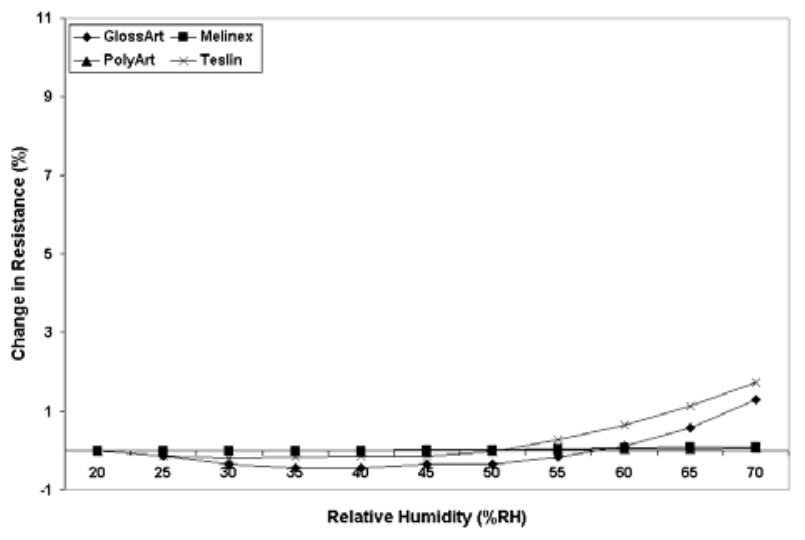

Fig. 5. Typical Relative Humidity - Resistance plots for sandwich structure deposited on each substrate

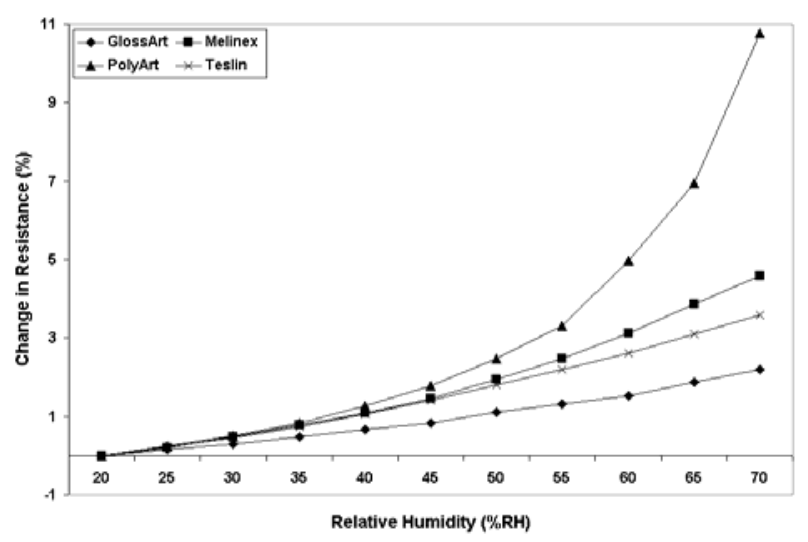

Fig. 6. Typical Relative Humidity - Resistance plots for planar structure deposited on each substrate

type deposited on the four substrates when exposed to extremes of humidity.

Considering the results attained for sandwich structures, it is noticeable that little change in resistance occurs for the structures deposited on PolyArt and Melinex. Equally, little change in resistance is noted for structures deposited on the remaining substrates to $50 \% \mathrm{RH}$, after

which, the resistance of the GlossArt and Teslin deposited structures begin to increase noticeably. This trend is quantifiable by considering the percentage change in resistance values at $50 \% \mathrm{RH}$ and $70 \% \mathrm{RH}$, detailed in Table 4. Both GlossArt and Teslin deposited structures exhibit a decrease in nominal structure resistance up to $60 \% \mathrm{RH}$ and $55 \% \mathrm{RH}$ respectively before resistance increases at a rapid rate.

Results gained for planar structures, depicted in Fig. 6, present the largest changes in structure resistance due to changes in relative humidity. All substrate types experience a positive change in resistance with increased humidity levels. Generally the change in resistance is of a highly linear nature, with the exception of structures deposited on the PolyArt substrate, which also possessed the greatest change in resistance. At 55\%RH, the resistance of PolyArt deposited structures is within 100\% of other structures at this humidity level. Beyond this point, however, the resistance of the PolyArt samples increases at a far greater rate than the remaining structures.

Relative Humidity - Resistance data gathered for plain structures deposited on each substrate followed a similar trend to those gathered from sandwich structures in that

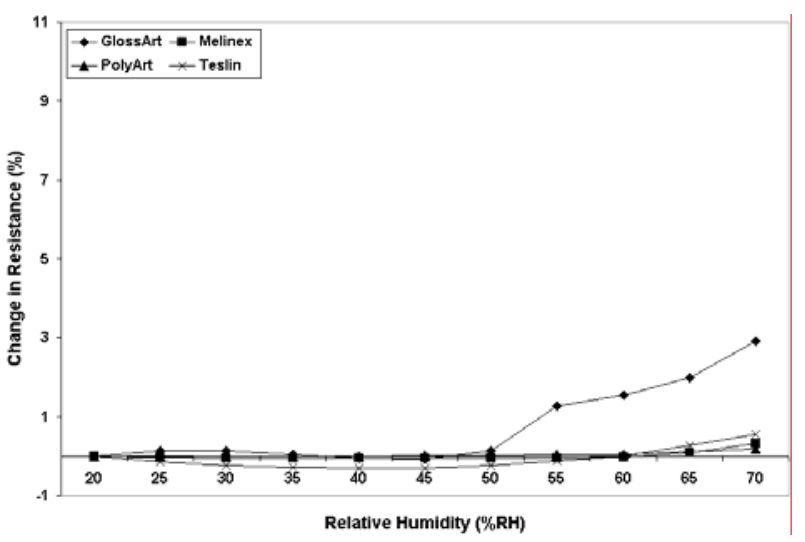

Fig. 7. Typical Relative Humidity - Resistance plots for plain structure deposited on each substrate

\begin{tabular}{|c|c|c|c|c|}
\hline & Substrate & $\begin{array}{c}\% \Delta \mathrm{R}- \\
50 \% \mathrm{RH}\end{array}$ & $\begin{array}{c}\% \Delta \mathrm{R}- \\
70 \% \mathrm{RH}\end{array}$ & $\begin{array}{c}\text { RHCR } \\
\left(* 10^{-3} / \% \mathrm{RH}\right)\end{array}$ \\
\hline \multirow{4}{*}{$\begin{array}{l}\frac{5}{3} \\
\frac{0}{3} \\
\text { 怘 }\end{array}$} & GlossArt & -0.360 & 1.291 & -0.1201 \\
\hline & PolyArt & 0 & 0.062 & 0 \\
\hline & Teslin & -0.018 & 1.733 & -0.0062 \\
\hline & Melinex & 0.018 & 0.079 & 0.0058 \\
\hline \multirow{4}{*}{$\begin{array}{l}\text { 营 } \\
\frac{\pi}{2}\end{array}$} & GlossArt & 1.112 & 2.194 & 0.3706 \\
\hline & PolyArt & 2.486 & 10.771 & 0.8286 \\
\hline & Teslin & 1.803 & 3.593 & 0.6007 \\
\hline & Melinex & 1.938 & 4.590 & 0.6460 \\
\hline \multirow{4}{*}{$\frac{\text { 쥼 }}{2}$} & GlossArt & 0.133 & 2.908 & 0.0398 \\
\hline & PolyArt & 0.018 & 0.180 & 0.0059 \\
\hline & Teslin & -0.241 & 0.543 & -0.0803 \\
\hline & Melinex & -0.058 & 0.311 & -0.0194 \\
\hline
\end{tabular}

Table 4. \% change in resistance at 50\%RH and 70\%RH and RH coefficient of resistance

little change in resistance is noticed up to $50 \% \mathrm{RH}$. As with the sandwich structures, at $50 \% \mathrm{RH}$ PolyArt deposited structure experienced the least change in resistance, amounting to $0.018 \%$, while the greatest change in resistance was noticed in structures deposited on Teslin, $-0.241 \%$. Beyond 50\%RH all structures exhibit an increase in resistance due to humidity, with GlossArt deposited structures attaining a noticeable larger increase than other structures, amounting to $2.908 \%$ at $70 \% \mathrm{RH}$. The second highest increase in resistance is experienced by Teslin deposited structures at $0.543 \%$ followed by Melinex and PolyArt.

Due to the extreme non-linearity of data gathered by the majority of samples beyond 50\%RH, Relative Humidity Coefficients of Resistance (RHCR) values were calculated for each structure by considering results gained in the region of $20 \% \mathrm{RH}-50 \% \mathrm{RH}$ using equation (1),

$R H C R=\left(\frac{1}{R}\right) *\left(\frac{\Delta R}{\Delta \% R H}\right)$

where $\mathrm{R}$ represents structure nominal resistance and $\Delta \mathrm{R}$ and $\Delta \% \mathrm{RH}$ represent the change in structure resistance and change in relative humidity, respectively.

By considering RHCR values, listed in table 4, it becomes apparent that planar structures are more susceptible to changes in resistance due to increased relative humidity than any other structure. All planar structures attained positive RHCR values for the range $20 \%-50 \% \mathrm{RH}$ and, in general, they are between $10-100$ 


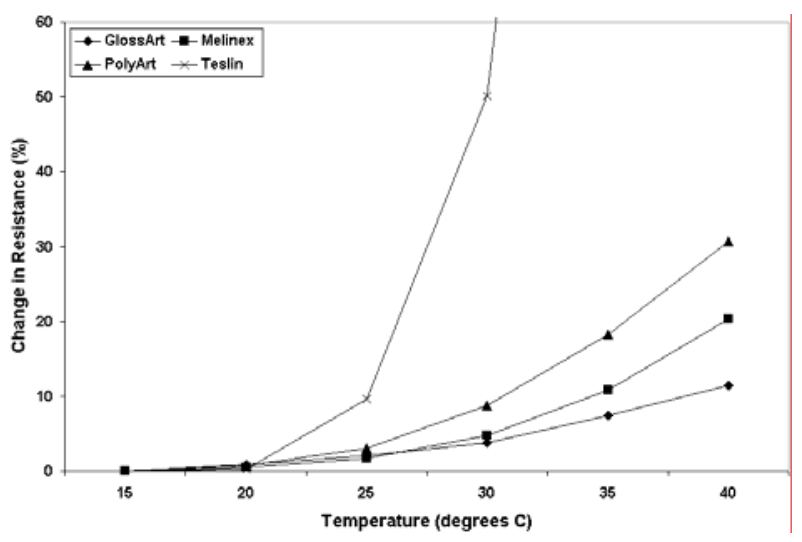

Fig. 8. Typical Temperature - Resistance plots for sandwich structure deposited on each substrate

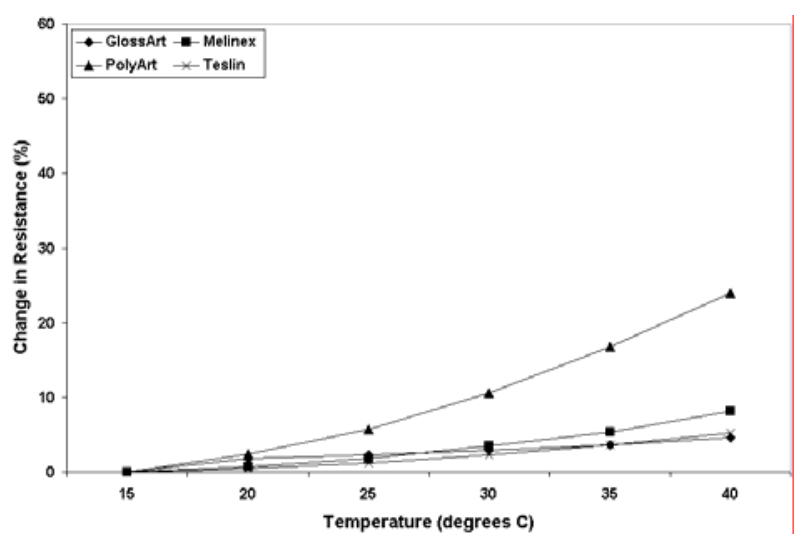

Fig. 9. Typical Temperature - Resistance plots for planar structure deposited on each substrate

times more sensitive to humidity than the two remaining structure types when deposited on each substrate material.

Sandwich and plain structure suffer from changes in resistance due to changes in humidity to similar degrees. For both structure types Teslin is the only substrate where negative RHCR values are obtained, while the RHCR value for PolyArt deposited sandwich structures is 0 , suggesting that this structure type deposited on this substrate is immune to the effects of humidity.

\subsection{Temperature - Resistance}

Figs. $8-10$ detail typical percentage change in resistance results for all types of structures deposited on the four differing substrates when exposed to changes in ambient temperature.

Unlike changes in resistance caused by changes in relative humidity, all structures experience a positive change in resistance due to changes in ambient temperature.

Results gained for sandwich structures, illustrated in Fig. 8, suggest that structures deposited on the Teslin substrate are affected greatly by changes in temperature. This fact is numerically represented in Table 5 where the percentage change in resistance at $30^{\circ} \mathrm{C}$ and $40^{\circ} \mathrm{C}$ are listed.

Fig. 9 details responses gained from planar structures deposited on each substrate material. When compared to results gained from other structures, it becomes apparent that changes in resistance gained from planar structures are much more linear in nature than results gained from

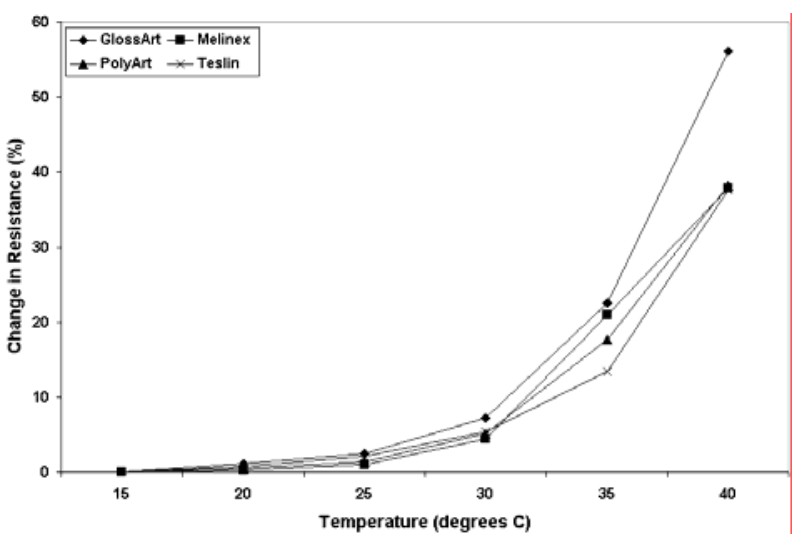

Fig. 10. Typical Temperature - Resistance plots for plain structure deposited on each substrate

\begin{tabular}{|c|c|c|c|c|}
\hline & Substrate & $\% \Delta \mathrm{R}-30^{\circ} \mathrm{C}$ & $\% \Delta \mathrm{R}-40^{\circ} \mathrm{C}$ & $\begin{array}{c}\alpha \\
\left(* 10^{-3} /{ }^{\circ} \mathrm{C}\right)\end{array}$ \\
\hline \multirow{4}{*}{$\begin{array}{l}\frac{5}{5} \\
\text { 䓌 } \\
\text { 芯 }\end{array}$} & GlossArt & 3.799 & 11.398 & 2.5331 \\
\hline & PolyArt & 8.775 & 30.715 & 5.8507 \\
\hline & Teslin & 50.114 & 1036.188 & 33.4092 \\
\hline & Melinex & 4.725 & 20.318 & 3.1503 \\
\hline \multirow{4}{*}{$\begin{array}{l}\text { 尝 } \\
\frac{\pi}{2}\end{array}$} & GlossArt & 2.927 & 4.634 & 1.9512 \\
\hline & PolyArt & 10.542 & 23.929 & 7.0283 \\
\hline & Teslin & 2.291 & 5.195 & 1.5271 \\
\hline & Melinex & 3.481 & 8.173 & 2.3209 \\
\hline \multirow{4}{*}{$\frac{\pi}{\frac{\pi}{2}}$} & GlossArt & 7.207 & 56.081 & 4.8048 \\
\hline & PolyArt & 5.077 & 38.189 & 3.3848 \\
\hline & Teslin & 5.369 & 37.584 & 3.5794 \\
\hline & Melinex & 4.372 & 37.833 & 2.9151 \\
\hline
\end{tabular}

Table $5 . \%$ change in resistance at $30^{\circ} \mathrm{C}$ and $40^{\circ} \mathrm{C}$ and temperature coefficient of resistance

other structure types. By comparing the numerical values listed in Table 5, it also becomes apparent that at the upper temperature limit of $40^{\circ} \mathrm{C}$, planar structures (with the exception of PolyArt) present the least change in resistance.

Graphical representation of changes in resistance due to changes in temperature for plain structures when deposited on each substrate type are depicted in Fig. 10. As with sandwich structures, changes in resistance for plain structures are of a highly non-linear nature. However, with the exception of the result gained for GlossArt deposited structures at $40^{\circ} \mathrm{C}$, the results gained for each substrate are of a consistent nature. This is more apparent, when comparing the numerical values presented in Table 5 , for changes in resistance at $30^{\circ} \mathrm{C}$ and $40^{\circ} \mathrm{C}$.

As with results gained for relative humidity, due to the non-linear nature of results gained for sandwich and plain structures and for the purpose of comparison, Temperature Coefficient of Resistance $(\alpha)$ values have been calculated over the range of $15^{\circ} \mathrm{C}-30^{\circ} \mathrm{C}$ and are detailed in Table 5.

$\alpha=\left(\frac{1}{R}\right) *\left(\frac{\Delta R}{\Delta T}\right)$

Equation (2) was used to calculate $\alpha$ values where $\mathrm{R}$ represents nominal structure resistance and $\Delta \mathrm{R}$ and $\Delta \mathrm{T}$ represent change in resistance and change in temperature, respectively.

By comparing $\alpha$ values for structures deposited on all substrates, it becomes apparent that changes in ambient 


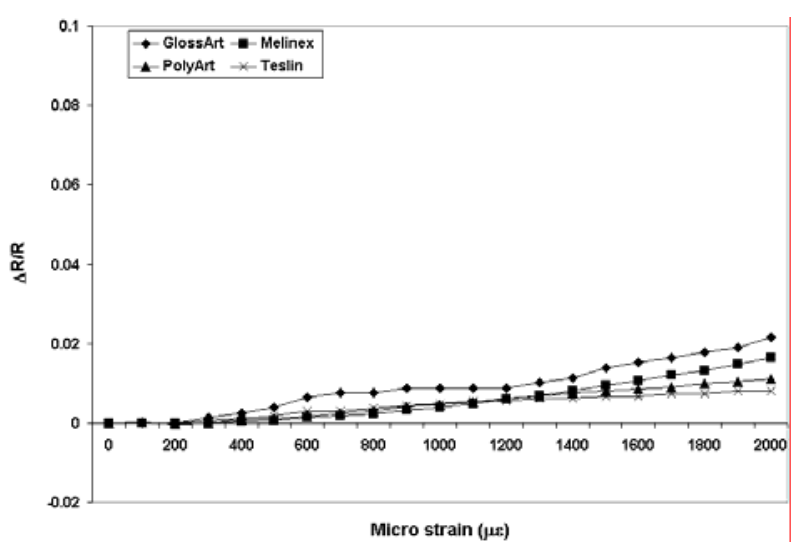

Fig. 11. Typical Strain - Resistance plots for sandwich structure deposited on each substrate

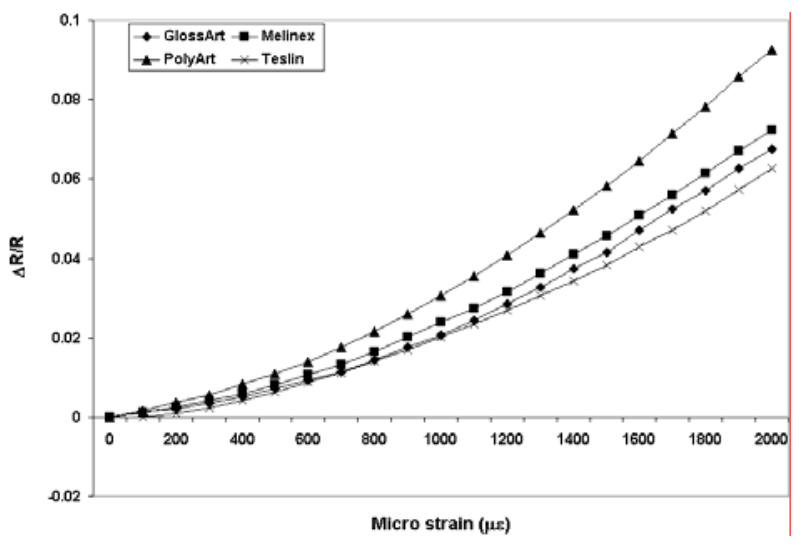

Fig. 12. Typical Strain - Resistance plots for planar structure deposited on each substrate

temperature in the range of $15^{\circ} \mathrm{C}-30^{\circ} \mathrm{C}$ affect planar structures the least, such that three of the lowest $\alpha$ values are attained by this structure type. The exception is PolyArt deposited planar structures, which exhibit a typical $\alpha$ value of $7.0283 * 10^{-3} /{ }^{\circ} \mathrm{C}$. Generally $\alpha$ values calculated for the remaining structures are

similar, varying from $2.5331 * 10^{-3} /{ }^{\circ} \mathrm{C}$ to $5.8507 * 10^{-3} /{ }^{\circ} \mathrm{C}$, with the exception of Teslin sandwich structures which possess a typical $\alpha$ value of $33.4092 * 10^{-3} /{ }^{\circ} \mathrm{C}$, suggesting that these structures are highly unstable when exposed to extremes of temperature. $\alpha$ values are in keeping with results attained from previous work [11,13].

\subsection{Strain - Resistance}

Typical responses gained from each structure type, when deposited on each substrate while undergoing strain analysis, are detailed in Figs. $11-13$.

Gauge factor (GF) values have been calculated using data gathered and are used to numerically represent the sensitivity of each structure in relation to strain.

$G F=\frac{\Delta R / R}{\varepsilon}$

Equation (3) was used to calculate gauge factor values where $\Delta R / R$ represents the fractional change in structure resistance and $\varepsilon$ represents strain.

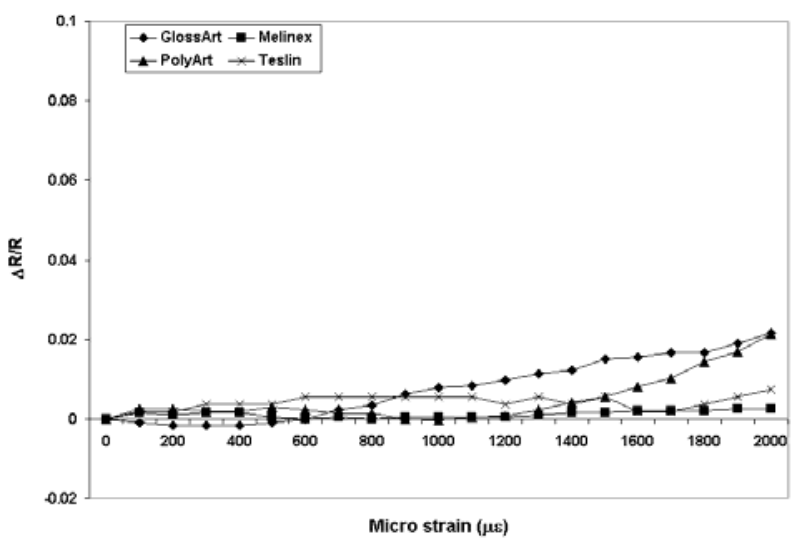

Fig. 13. Typical Strain - Resistance plots for plain structure deposited on each substrate

\begin{tabular}{|c|c|c|c|}
\hline & Substrate & Gauge Factor & $\mathrm{R}^{2}$ value \\
\hline \multirow{4}{*}{ 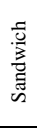 } & GlossArt & 10.787 & 0.967 \\
\hline & PolyArt & 5.502 & 0.983 \\
\hline & Teslin & 4.019 & 0.973 \\
\hline & Melinex & 8.217 & 0.932 \\
\hline \multirow{4}{*}{$\begin{array}{l}\text { 壱 } \\
\text { 売 }\end{array}$} & GlossArt & 33.795 & 0.958 \\
\hline & PolyArt & 46.278 & 0.968 \\
\hline & Teslin & 31.341 & 0.966 \\
\hline & Melinex & 36.224 & 0.966 \\
\hline \multirow{4}{*}{$\frac{\text { 䨌 }}{2}$} & GlossArt & 10.779 & 0.953 \\
\hline & PolyArt & 10.623 & 0.548 \\
\hline & Teslin & 3.745 & 0.177 \\
\hline & Melinex & 1.243 & 0.385 \\
\hline
\end{tabular}

Table 6. Gauge Factor and $\mathrm{R}^{2}$ value for each structure

It is evident from Figs. 11 and 13, that sandwich and plain structures attain similar changes in resistance over the range $0-2000$ micro strain when compared to results gained for planar structures, Fig 12. This can be numerically confirmed by considering GF values noted in Table 6. GF values for sandwich and plain structures lie in the region of $1.2-10.7$ while the lowest GF value attained for planar structures is about $300 \%$ higher than the highest GF gained from the other two structure types, at 31.3.

By comparing GF values for each structure type, it is possible to conclude that planar structures have a much higher degree of consistency than any other structure type. The difference in GF values for planar structures is about $47 \%$ while the difference in GF values for sandwich and plain structures deposited on different substrates is more than $200 \%$ and $700 \%$, respectively. This suggests that planar structures are less substrate reliant than the remaining structures. Metal foils gauges generally attain GF values of 2-4 depending on sensing material, while previous polymer thick film sensors have attained GF values ranging from 8-14, [6-11].

Linearity of response is an important issue when considering sensor design. To represent the linearity of response for structures in this analysis, $\mathrm{R}^{2}$ values have been generated. An $\mathrm{R}^{2}$ value of 1 would suggest perfect linearity of response. As with GF values, $\mathrm{R}^{2}$ values attained for planar structures deposited on various substrates are fairly consistent, while values attained for both sandwich and plain structures vary greatly due to substrate material.

The planar devices, followed closely by sandwich devices, attained the highest average linearity for structures printed on all substrates, while plain silver 


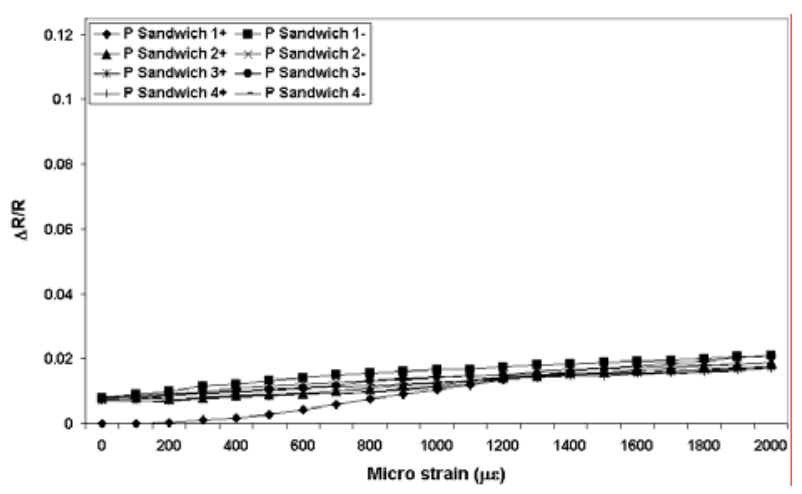

Fig. 14. Typical Strain - Resistance repeatability characteristics for sandwich structures

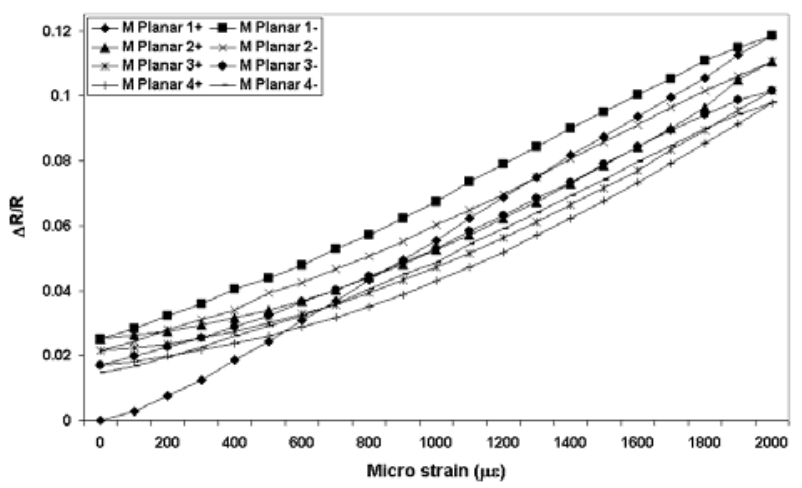

Fig. 15. Typical Strain - Resistance repeatability characteristics for planar structures

sensors performed worst with regards to linearity. Teslin deposited plain structures in particular, achieved an $\mathrm{R}^{2}$ value of 0.177 , suggesting very little relationship between applied strain and change in resistance.

Figs. 14 - 16 display typical repeatability responses for each structure type. It is apparent that all structure types suffer from both hysteresis and drift problems to differing degrees. Common to all structures is a high level of hysteresis during the first cycle of straining, after which, hysteresis reduces dramatically. Sandwich structures suffer the least from the effects of hysteresis and drift, while planar and plain structures are influenced severely.

Fig. 16, for plain devices, displays clearly an inconsistent relationship between strain and change in resistance, suggesting that this type of structure could not be used reliably for a strain sensor.

\subsection{Discussion}

The differences between changes in structure resistance due to applied strain noticed for the three differing sensor types, are attributed mainly to the nature of the active particulate used in the two inks considered. For the purpose of understanding the changes in resistance due to strain it is necessary to consider initially the planar (graphite) and plain (silver) structures. Table 7, details the characteristics of the conductive phase of each ink. The plain structures are constructed from a silver loaded ink constituting a large portion of silver flake, while the planar structures are formed using an ink where the active material is a graphite powder, each particulate in the shape of a spheroid.

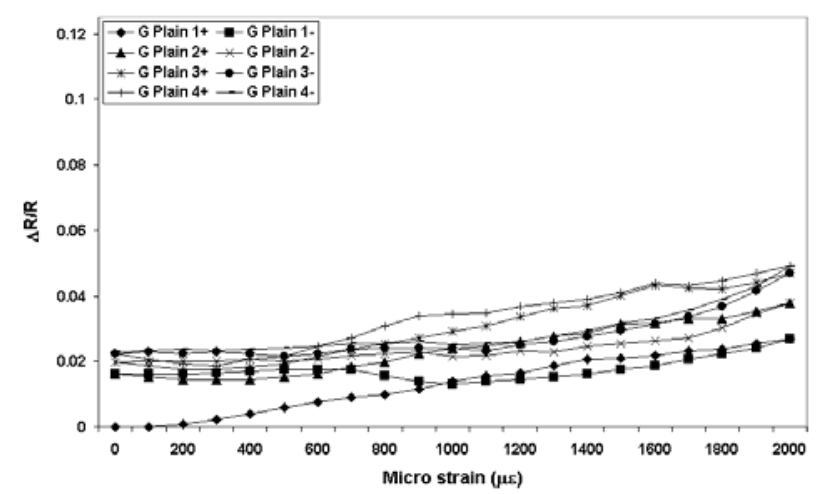

Fig. 16. Typical Strain - Resistance repeatability characteristics for plain structures

\begin{tabular}{|c|c|c|c|}
\hline Particulate & $\begin{array}{c}\text { Particulate size } \\
\text { distribution } \\
\text { (mean, } \mu \mathrm{m} \text { ) }\end{array}$ & $\begin{array}{c}\text { Specific surface } \\
\text { area } \\
\left(\mathrm{m}^{2} / \mathrm{g}\right)\end{array}$ & $\begin{array}{l}\text { Particulate } \\
\text { shape }\end{array}$ \\
\hline $\begin{array}{l}\text { Silver RA- } \\
0001\end{array}$ & $\mathrm{~d}_{10}=1, \mathrm{~d}_{50}=4, \mathrm{~d}_{90}=13$ & $1.10-1.70$ & Flake \\
\hline $\begin{array}{l}\text { Graphite } \\
\text { KS6 }\end{array}$ & $\begin{array}{c}\mathrm{d}_{10}=1.6, \mathrm{~d}_{50}=3.4, \\
\mathrm{~d}_{90}=6.5\end{array}$ & 20 & $\begin{array}{l}\text { Irregular } \\
\text { spheroids }\end{array}$ \\
\hline
\end{tabular}

Table 7. Conductive particulate description

The change in structure resistance with strain is caused by separation of conductive particles within the deformed ink films. It has been proved that ink films formed from the graphite ink are more sensitive to strain than similar films formed using the silver ink. This is due to the shape of particulates in each ink. The spheroid nature of the particulates in the graphite ink means that actual separation between particles occur, resulting in a large increase in resistance. The flake nature of the silver ink means that two particulates may slide across each other during straining, while maintaining contact. This effect means that while flakes are still in contact, the proportion of contact between two flakes decreases, thus increasing resistance.

Due to the composition of sandwich structures, both effects evident in the silver and graphite inks occur, though the relatively low sheet resistivity of the silver electrodes compared to the graphite sensing layer denotes that much of the change in resistance occurs through the silver ink, resulting in low gauge factor values for this type of structure. However, the presence of the graphite sensing layer acts as a smoothing boundary, resulting in good linearity of response and good reproducibility.

Hysteresis during repeated cyclical straining tests is ascribed to a viscoelastic effect occurring in the printed ink film, generating a slight delay between applied strain and actual particulate separation. Local monitoring of relative humidity and temperature during strain testing suggests that the drift effect noticed between repeated cyclical loading - unloading is due to mechanical settling of the ink, rather than changes in resistance due to a culmination of changes in both temperature and relative humidity.

Two factors are believed to be dominant in explaining the increase in resistance which results from the raising of temperature. The first, and most dominant is concerned with the temperature coefficient of resistance values for the active material in each ink film. The TCR value for silver is approximately eight times greater than that of graphite, explaining why the resistance change of plain 
silver structures is much greater than that of the graphite planar structures. The second factor is understood to be a thermal straining effect caused by the expansion of both substrate material and vehicle phase of ink at relatively low temperatures. The effect of this is similar to the explanation of changes in resistance during strain testing.

\section{Conclusions}

The characteristics of three alternative strain sensitive structures (sandwich, planar and plain) deposited on an array of differing substrate materials manufactured via the conductive lithographic film printing process, have been presented. Data regarding changes in resistance due to changes in relative humidity, temperature and strain has been collected. While the resistance of all structures is affected by changes in both relative humidity and temperature, local monitoring of these parameters during strain testing indicated that they have negligible effect on the strain measurements collected. Planar structures, composed from a graphite loaded conductive ink, prove to be far more sensitive to strain than both plain silver and silver/graphite sandwich configuration sensors. This response is attributed to the spheroid nature of the graphite particulates when compared to the flake nature of the silver particulates. The increased sensitivity is reflected in the superior gauge factor values attained for planar structure, being more than three times greater than GF values attained for either plain or sandwich configurations. Planar structures also attained the greatest degree of response linearity. The presence of hysteresis apparent during repetitive cyclical loading - unloading testing is ascribed to the viscoelastic nature of the vehicle phase of the printed ink film, whilst drift between cycles in considered to be due to mechanical settling of the ink film.

GF values attained for lithographically printed silvergraphite strain sensors are in general greater than those possessed by more convention commercially available metal foil gauges. However, poor hysteresis, zero drift and linearity characteristics would prove to be unacceptable in high tolerance strain measurement. At this stage in development it is considered that lithographically printed silver-graphite strain sensors are not appropriate for high tolerance strain measurement, but are suitable as complimentary components in CLF printed, low cost, low life cycle, disposable applications. 


\section{References}

1 C. C. Perry and H. R. Lissner, The strain gage primer, McGraw Hill, New York, $2^{\text {nd }}$ edn., 1962, pp. 1-9.

2 B. J. Ramsey, P. S. A. Evans and D. J. Harrison, A novel circuit fabrication technique using offset Lithography, J. of Electron. Manuf., 7 (1) (1997) 63 - 67.

3 N. S. Leyland, J. R. G. Evans and D. J. Harrison, Lithographic printing of force - sensitive resistors, J. of Mater. Sci.: Mater. El. (13) (2002) $387-390$.

4 P.R. Shepherd, C. Taylor, P.S.A. Evans and D. J. Harrison, Measurement and modelling of MIC components using conductive lithographic films, 31st European Microwave Conference, London, UK, Sept $25-27,2001$.

5 P. Harrey, G. Hay and D. Harrison, Capacitive- type humidity sensors manufactured using offset lithography, Eurosensors XVI Conference, Prague, Czech Republic, Sept 15 - 18, 20021067 - 1070.

6 M. Prudenziati, B. Morten and A. Taroni, Characterization of thickfilm resistor strain gauges on enamel steel, Sensors and Actuators, 2 (1981/82) $17-27$.

7 K. I. Arshak, F. Ansari and D. Collins, Analysis of thick film strain resistors on stainless steel and ceramic substrates, Int. J. Electron., 76 (2) (1994) $365-376$.

8 G. Harsanyi, Polymer thick-film technology: a possibility to obtain very low cost pressure sensors?, Sensors and Actuators A, 25 - 27 (1991) 853 - 857.

9 C. Canali, D. Malavasi, B. Morten, M. Prudenziati and A. Taroni, Strain sensitivity in thick-film resistors, IEEE Trans. Components, Hybrids Manufact. Technol., Chmt - 3 (3) (1980) 421 - 423.

10 L. Fraigi and L. Malatto, Thick-film weldable strain gauges, Sensors and Actuators A, 46 - 47 (1995) 222 - 224.

11 K. I. Arshak, A. K. Ray, C. A. Hogarth, D. G Collins and F. Ansari, An analysis of polymeric thick-film resistors as pressure sensors, Sensors and Actuators A, 49 (1995) $41-45$.

P. S. A. Evans, P. Harrey, B. Ramsey and D. J. Harrison, Lithographic Film Circuits - A Review, Circuit World (J. of Inst. Circuit Technology), 27 (3) (2001) 31 - 34.

13 G. I. Hay, P. S. A. Evans, D. J. Harrison, D. Southee, G. Simpson and P. M. Harrey, Characterization of Lithographically Printed Resistive Strain Gauges, IEEE Sensors Journal : Accepted for future publication. PP (Issue 99) (2005) 1 - 8 .

14 R. M. Scarisbrick, Electrically Conductive Mixtures, J. Phys D: Appl. Phys., 6 (1973) 2098 - 2110.

\section{Biographies}

Gareth Hay attained a BSc. (Hons) degree in Industrial Design from the Design Department at Brunel University in 2001. Following this he joined the Cleaner Electronics Research Group within the Department of Design at Brunel University as a Post Graduate Researcher enrolled on a $\mathrm{PhD}$ program. Current research concerns the printing of strain and pressure sensors by means of the Offset Lithographic Film printing process. He is due to complete his PhD in September 2005.

Dr. Peter Evans received the Ph.D. degree in mixed signal I.C. testability from the University of Huddersfield, Huddersfield, U.K., in 1994. He is a Lecturer in Engineering Design at Brunel University and a member of the EPSRC's College for Design and Integrated Production. He is a Chartered Electrical Engineer, and works in the field of novel circuit fabrication and interconnect technologies. He has 10 years experience in land mobile radio systems, acquired in Industry and in the Communications Research Group of the University of Bath, subsequently undertaking research in I.C. testability at Bath, and later at Huddersfield University, where he devised "Transient Response Analysis", a test strategy for analogue systems embedded in mixedsignal integrated circuits. He has published over thirty papers, and is a
Member of the IEE, the IEEE, and the IEEE Test Technology Technical Council.

Professor David Harrison, B.Sc. degree in Engineering Science, awarded by Exeter University, Exeter, U.K., and Ph.D. degree in Robotics from Portsmouth Polytechnic, Portsmouth, U.K., is the Head of research, a founder of the environmentally sensitive design group at Brunel University and one of the original investigators in the field of ADSM. Also a Member of the Institute of Electrical Engineers and a Chartered Engineer. Has successfully patented and licensed novel technologies in Printed Electronics. He also sits on EPSRC panels on Sustainable Technology and Designing for the 21st Century.

Darren Southee spent eight years working in the electronics industry in service, production and design roles. He designed the TD201 Digital Storage Adapter for THANDAR Electronics Ltd (1987) and the TA320 Logic Analyser for TTi Ltd (1992). He received a B.Eng. degree from the University of Hull, Hull, UK. His academic career has included roles at Bournemouth University, Bournemouth, UK - researching noninvasive blood sugar measurement, for Bradford University (Etisalat College of Engineering, Sharjah, United Arab Emirates) and the University of Lincoln (Hull Campus, UK). He is currently Course Director for the BA in Industrial Design \& Technology at Brunel University and a member of the Cleaner Electronics Research Group.

Dr. George Simpson lectures in the mechanical engineering aspects of design at Brunel University. His interests encompass structures, dynamics, vibrations, fluid mechanics, heat transfer, mathematics and engineering analysis. Prior to taking up his appointment with Brunel University in 1994 he spent seventeen years in industry in engineering design consultancy with YARD Ltd and BAeSEMA, latterly as a principal consultant and section head for computational fluid dynamics. $\mathrm{He}$ is a Chartered Engineer and Chartered Mathematician, and a Member of the Institution of Mechanical Engineers, and of the Institute of Mathematics and its Applications. He is currently the Course Director for two design courses at Brunel University; BSc Product Design Engineering and MEng Mechanical Engineering \& Design. His research interests include human soft tissue modelling, computational fluid dynamics and biomimetics.

Dr. Blue Ramsey obtained a $1^{\text {st }}$ Class Honours Degree in Industrial Design in 1995, and a Ph.D. in electronic materials and manufacturing in 1999, both from the Department of Design at Brunel University. He is currently employed in the School of Engineering and Design, Brunel University. Blue has co-investigated or worked five EPSRC grants within the Cleaner Electronics Research Group and has recently completed his successful 'First Grant' on printed thermocouple fabrication. He has published over 20 papers including 14 refereed journal publications and is a named inventor on two granted and licensed university patents. 